lead to water losses, such as diabetes. The patient's low level of consciousness was thought at first to be due to buprenorphine, while the other signs were attributed to septicaemia.

Hypernatraemia is managed by giving $5 \%$ dextrose to bring the plasma sodium concentration down to the normal range, taking care not to produce water intoxication. Cerebral oedema may follow overrapid dilution of plasma at a time when the brain cells have a high sodium content. These patients usually have a pronounced diuresis with a large sodium output due to the hyperosmolality of plasma, and diuretics are not needed. ${ }^{3}$ Because of massive diuresis they also lose potassium, which will need replacement.

${ }^{1}$ Marsden PD. Helminthic diseases: echinococcus granulosus. In: Beeson PB, MrDermott W, eds. Cecil-Loeb's textbook of medicine. 13th ed. London: W B Saunders, 1971:744.

${ }^{2}$ Kattan YB. Intrabiliary rupture of hydatid cyst of the liver. Ann $R$ Coll Surg Engl 1977;59:108-13.

${ }^{3}$ Schwartz WB. Disorders of fluid, electrolyte and acid base balance. In Beeson PB, McDermott W, eds. Cecil-Loeb's textbook of medicine. 13th ed. London: W B Saunders, 1971:1624.

(Accepted 11 February 1982)

Addenbrooke's Hospital and University Department of Surgery, Cambridge CB2 2QQ

$H M$ WANNINAYAKE, MB, FFARCS, senior registrar in anaesthetics

W BROUGH, MB, FRCS, registrar in surgery

N BULLOCK, MB, FRCS, senior registrar in surgery

R Y CALNE, FRS, FRCS, professor of surgery

J V FARMAN, MB, FFARCS, consultant anaesthetist

\section{Pulmonary infiltration and bone marrow depression complicating treatment with amiodarone}

Amiodarone is valuable in recurrent cardiac arrhythmias. Recognised side effects include corneal deposits, photosensitisation, skin discoloration, ${ }^{1}$ and disorders of thyroid function. ${ }^{2}$ We report a case in which treatment with amiodarone resulted in pulmonary infiltration and bone marrow depression.

\section{Case report}

A 71-year-old man had mild hypertension, ischaemic heart disease, and chronic airways obstruction. In 1972 he developed recurrent supraventricula tachyarrhythmias, poorly controlled by established drugs, and required cardioversion on two occasions. Amiodarone $200 \mathrm{mg}$ twice daily was started in 1979 and his arrhythmias stopped. Later that year he developed photosensitivity, and during 1980 corneal deposits were noted. He also received bendrofluazide $5 \mathrm{mg}$ daily for his hypertension.

The patient remained well until July 1981, when he was admitted to hospital after a syncopal attack. He complained of increasing breathlessness and fatigue developing over five weeks. Examination showed a plethoric man with bluish pigmentation and thickening of the skin around the nose and cheeks. Pulse rate was 56 beats $/ \mathrm{min}$, and blood pressure $140 / 80 \mathrm{~mm} \mathrm{Hg}$ There was no evidence of cardiac failure. Fine inspiratory crackles were heard at the lung bases.

Electrocardiography showed diffuse myocardial ischaemia. Haemoglobin concentration was $9.2 \mathrm{~g} / \mathrm{dl}$ (indices indicating a normochromic, normocytic anaemia); white cell count $5 \cdot 0 \times 10^{9} / 1$ (normal differential); platelet coun $200 \times 10^{9} / 1$; erythrocyte sedimentation rate $120 \mathrm{~mm}$ in first hour; and blood urea concentration $14.2 \mathrm{mmol} / 1(85 \mathrm{mg} / 100 \mathrm{ml})$. Electrolyte concentrations and liver function values were normal. Lactate dehydrogenase activity was $920 \mathrm{IU} / 1$; serum haptoglobin was normal. The chest radiograph (figure) showed infiltration of the middle and lower zones of both lungs. Arteria oxygen pressure was $4.9 \mathrm{kPa}(37 \mathrm{~mm} \mathrm{Hg})$, and carbon dioxide pressure $4.1 \mathrm{kPa}(30 \mathrm{~mm} \mathrm{Hg})$. Forced expiratory volume in 1 second was 1.4 (predicted $2.75 \mathrm{l}$ ), and forced vital capacity 2.51 (predicted 4.01 ). Bone marrow was poorly cellular with large fat spaces; erythropoiesis was normoblastic. Thyroxine concentration was $43 \mathrm{nmol} / 1(3.3 \mu \mathrm{g} / 100 \mathrm{ml}$ ) (normal $50-160 \mathrm{nmol} / 1 ; 3 \cdot 9-12 \cdot 4 \mu \mathrm{g} / 100 \mathrm{ml})$; triiodothyronine resin uptake (Thyopac-3) $107 \mathrm{nmol} / \mathrm{l}(69 \cdot 7 \mathrm{ng} / \mathrm{ml})$ (normal 93-124 nmol $/ 1 ; 60 \cdot 5-80 \cdot 7$ $\mathrm{ng} / \mathrm{ml}$ ); free thyroxine index 40 (normal 54-172); and thyroid-stimulating hormone concentration $35 \cdot 7 \mathrm{mU} / 1$ (normal 0-8 mU/1). Precipitins for farmers' lung, bird-breeders' lung, and aspergillus were negative. Rheumatoid and antinuclear factors were not detected.

Amiodarone was thought to have induced both pulmonary infiltration and bone marrow depression. The drug was stopped and prednisone $40 \mathrm{mg}$ daily started. Within a week there was symptomatic and radiological improvement. Pulmonary function tests at one month showed spirometry unchanged, total lung capacity 6.11 (predicted $6.45 \mathrm{l}$ ), and carbon monoxide transfer factor $1.8 \mathrm{mmol} / \mathrm{min} / \mathrm{kPa}(5.3 \mathrm{ml} / \mathrm{min} / \mathrm{mm} \mathrm{Hg}$ ) (predicted $8.0 \mathrm{mmol} / \mathrm{min} / \mathrm{kPa}$ $23.9 \mathrm{ml} / \mathrm{min} / \mathrm{mm} \mathrm{Hg}$ ). Bronchoscopy showed increased secretions, and transbronchial biopsy showed cellular alveolar walls with clumps of alveolar macrophages but no fibrosis.

Two months after withdrawal of amiodarone the chest radiograph was virtually clear (figure) and pulmonary function tests showed improvement

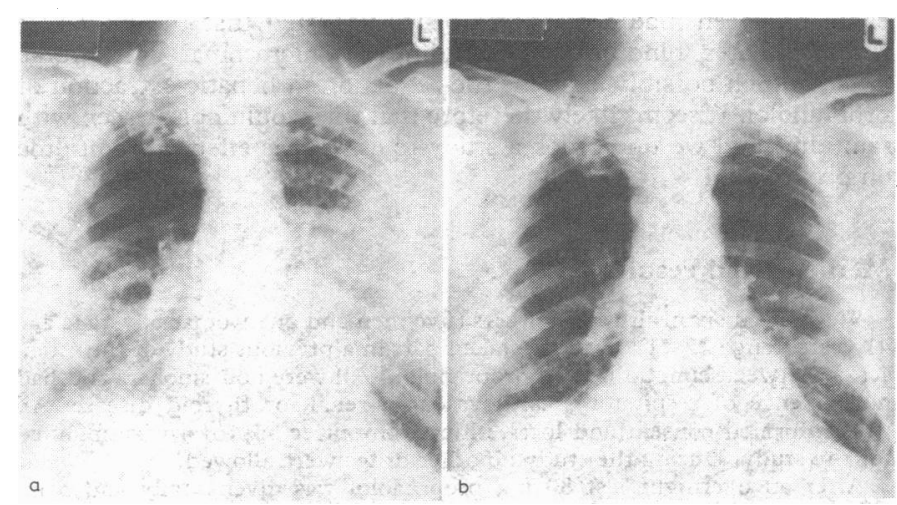

Chest radiographs (a) on presentation showing widespread infiltration, and (b) two months after withdrawal of amiodarone showing considerable clearing.

Haemoglobin concentration was $11.4 \mathrm{~g} / \mathrm{dl}$, but the marrow remained hypoplastic. Erythrocyte sedimentation rate fell to $15 \mathrm{~mm}$ in first hour. Thyroid function values returned to normal, but lactate dehydrogenase activity remained raised. Three months after the withdrawal of amiodarone the patient had an attack of cardiac pain and severe breathlessness and died at home. Necropsy confirmed coronary atheroma and pulmonary oedema. Histologically the lungs showed no evidence of intra-alveolar fibrosis.

\section{Comment}

Amiodarone apparently induced pulmonary infiltration and bone marrow depression in this patient. The pulmonary infiltration responded promptly to withdrawal of the drug and treatment with prednisone. Bone marrow hypoplasia was still present three months later at the time of necropsy.

Hypersensitivity pneumonitis ${ }^{3}$ and fibrosing alveolitis ${ }^{4}$ have been reported as complications of treatment with amiodarone. We contacted both the manufacturers of the drug and the Committee on the Safety of Medicines to find out whether they had been notified of similar side effects. Apparently there is free interchange of information between them. Including the present case, there had been five cases of pulmonary infiltration reported. No cases of bone marrow depression had been reported to either. The mechanism of induction of side effects is not clear, but their occurrence gives cause for concern.

We suggest that patients receiving amiodarone should be observed not only for corneal deposits, skin lesions, and thyroid function abnormalities but also for pulmonary infiltration and bone marrow depression.

1 Verin PH, Vildy A. The oculo-cutaneous effects of amiodarone. International congress and symposium series. No 16. London: Royal Society of Medicine, 1979:63-6.

${ }^{2}$ Rees LH, Ward DE, Al-Hamdi A. The effect of amiodarone on thyroid function. International congress and symposium series. No 16. London: Royal Society of Medicine, 1979:53-6.

${ }^{3}$ Rotmensch $\mathrm{H}$, Liron $\mathrm{M}$, Tupilski $\mathrm{M}$. Possible association of pneumonitis with amiodarone therapy. Am Heart $\mathcal{F} 1980 ; 100: 412-3$.

${ }^{4}$ Heger JJ, Prystowsky EN, Jackman WM, et al. Amiodarone: clinical efficacy and electrophysiology during long term therapy for recurrent ventricular tachycardia or ventricular fibrillation. $N$ Engl F Med 1981; $305: 539-45$.

(Accepted 2 February 1982)

Hexham General Hospital, Hexham, Northumberland NE46 1QJ

A J WRIGHT, MRCP, medical rẹgistrar (now at department of respiratory medicine, Freeman Hospital, Newcastle upon Tyne NE7 7DN) R G BRACKENRIDGE, FRCP, FRCPED, consultant physician 